\title{
THE EFFECT OF SELECTED HEALTH, DEMOGRAPHIC AND PSYCHOSOCIAL ASPECTS ON QUALITY OF LIFE IN PATIENTS WITH PERIPHERAL ARTERIAL OCCLUSIVE DISEASE - A PROSPECTIVE ANALYSIS
}

\author{
Ladislav Slováček ${ }^{1,2}$, Birgita Slováčková ${ }^{3}$,Vendelín Chovanec ${ }^{4}$, Petra Vacková ${ }^{1}$, Marie Kašlíková1, Helena Bohutínská 1 , \\ Ladislav Jebavy ${ }^{1,2}$
}

University of Defence, Faculty of Military Health Science, Hradec Králové, Czech Republic: Department of Field Internal Medicine ${ }^{1}$, Charles University in Prague, Faculty of Medicine and University Hospital in Hradec Králové, Czech Republic: 2nd Department of Internal Medicine, Division of Clinical Haematology 2, Department of Psychiatry ${ }^{3}$, Department of Radiology 4

Summary: Background. Peripheral arterial occlusive disease (PAOD) is a prevalent atherosclerotic disorder characterized by exertional limb pain, loss of limb, and a high mortality rate. Because of its chronic nature, it often has a negative impact on a patient quality of life (QoL). Aims. To evaluate the effect of selected health, demographic and psychosocial aspects on QoL in respondents with PAOD. Patients and Methods. The study is a prospective and cross-sectional. It was carried out at the 2nd Department of Medicine of Charles University Hospital at the Faculty of Medicine in Hradec Králové, Czech Republic. Forty two respondents with PAOD (28 male, 14 female) were evaluated. All the respondents had involvement of femoral and popliteal arterial circulation. The number of all respondents in accordance with Fontaine classification was as follows: intermittent claudication: stage IIa - 4, stage IIb $(<200 \mathrm{~m})-16$, stage IIb $(<50 \mathrm{~m})-9$, chronic limb ischaemia: stage III - 6, stage IV - 7. The average age of all respondents was 65,4 years old (age range 45-79 years old). The study evaluates the effect of health aspects (stage of PAOD in accordance with Fontaine classification, diabetes mellitus, arterial hypertension, hyperlipidaemia, obesity, smoking), demographic (age, sex) and psychosocial aspects (level of education, marital status, religion) on QoL in respondents with PAOD. The Czech version of the International Generic European Quality of Life Questionnaire - EQ-5D was used. Results. The statistical evaluation presents statistically a significant dependence of QoL in respondents with PAOD on age $(p<0,01)$ and the stage of PAOD in accordance with the Fontaine classification $(p<0,01)$. The effect of other health, demographic and psychosocial aspects was statistically insignificant. Conclusion. The results had shown that with an increasing age and with a serious stage of PAOD in accordance with Fontaine classification, the QoL declines. The global QoL in respondents with PAOD is low.

Key words: Quality of life; Quality of life questionnaire; Peripheral arterial occlusive disease

\section{Introduction}

Peripheral arterial occlusive disease (PAOD) is a prevalent atherosclerotic disorder characterized by exertional limb pain, loss of limb, and a high mortality rate (2). In the Czech population, there is a low prevalence of PAOD low than $2 \%$ in men younger than 50 years and in Czech women this values occur 10 years later. Intermittent claudication is the most common symptom in patients with PAOD (1). Endovascular revascularization (artery balloon and stent angioplasty) currently serves as an effective therapy for patients with high-grade stenoses of the proximal limb arterial segments $(1,2)$. Surgical revascularization usually is re- served for patients who present with severe aortoiliac disease (in whom long-term patency is likely to be achieved) and who have a low cardiovascular perioperative ischemic risk. All patients with PAOD, of any severity, must successfully normalize atherosclerosis risk factors and use antiplatelet therapies (1). PAOD as a chronic disease is associated with physical, psychological and social distress for elderly patients and their families (4). People with PAOD have a significant disability that also affects psychosocial and emotional aspects of their quality of life (QoL) $(5,10)$.

The World Health Organization defines the QoL as „subjectively perceived physical, mental and social well-being and not only absence of disease" (5-8). A broad definition 
of QoL includes duration of life, impairment, functional status (social, psychological, and physical), and health perceptions (5-8). QoL evaluation is carried out by means of generic and specific QoL questionnaires. Generic QoL questionnaires generally evaluate a patient's overall condition regardless of his disease. Specific QoL questionnaires are designed for the evaluation of a patient's overall condition in a particular type of disease. Modules are often used with these specific questionnaires. These modules are focused on specific symptoms and complaints in a particular type of disease (5-8).

\section{Material and methods}

We carried out a prospective and cross-sectional study in 42 in-patients with PAOD at the 2nd Department of Internal Medicine of Charles University Hospital and Faculty of Medicine in Hradec Králové, Czech Republic during 2006 (from January $1^{\text {st }} 2006$ to June $1^{\text {st }} 2006$ ). The reason for hospitalization in our patients was artery balloon angioplasty. We evaluated the effect of selected health aspects (stage of PAOD in accordance with Fontaine classification, diabetes mellitus, arterial hypertension, hyperlipidaemia, obesity, smoking), demographic (age, sex) and psychosocial aspects (level of education, marital status, religion) on QoL in respondents with PAOD. This study was approved by the Charles University Hospital Ethics Committee.

The stages of PAOD in accordance with Fontaine classification are characterized (3): stage I - asymptomatic, stage IIa - intermittent claudication, pain-free walking distance $>200 \mathrm{~m}$, IIb $(<200 \mathrm{~m})$ - intermittent claudication, pain-free walking distance $<200 \mathrm{~m}$, stage IIb $(<50 \mathrm{~m})-$ intermittent claudication, pain-free walking distance $<50 \mathrm{~m}$, III - rest pain, IV - ischaemic lesion (ulcer, gangrene, necrosis).

The evaluation of QoL in respondents with PAOD was performed by means of the Czech version of the International Generic European Quality of Life Questionnaire EQ-5D Version (5-9). Query sheet values represent 2 markers of QoL - objective and subjective. The objective marker includes 5 dimensions of QoL: mobility, self-sufficiency, daily activity, pain/difficulty, distress/depression. To each question there were three grades of answers to express the grade of difficulty (without any difficulties, with medium difficulties, with heavy difficulties). There are 243 combinations of health conditions all together. The outcome is EQ-5D score (dimension of QoL) with values $0-1$ ( 0 - the worse health condition, 1 - the best health condition). The subjective marker represents a visual analog scale, where a value of 100 means the best health condition, and a value of 0 means the worse health condition. The participants marked on the chart (so called thermometer) their subjective perceived health condition. The outcome is EQ-5D VAS (subjective health condition). It gains the values 0-100 (5-9).

Statistical analysis was determined by means of analysis of variance. The descriptive analysis was used for evaluating the QoL questionnaire. The value $\mathrm{p}<0,05$ was considered significant. The statistical analysis was conducted through the StatSoft STATISTICA Base 7.1 version.

\section{Results}

The total number of respondents with PAOD was 42 (28 male, 14 female). All the respondents had involvement of femoral and popliteal arterial circulation. The number of all respondents in accordance with Fontaine classification was as follows: intermittent claudication: stage IIa - 4, stage IIb $(<200 \mathrm{~m})-16$, stage IIb $(<50 \mathrm{~m})-9$, chronic limb ischaemia: stage III -6 , stage IV -7 . The average age of all respondents was 65.4 years old (age range 45-79 years old). The number of respondents with diabetes mellitus was 26, with arterial hypertension 34, with hyperlipidaemia 28 . The number of liparous respondents with PAOD was 23 and the number of smokers was 30 . The number of respondents with secondary and university level education was 18 , and the number of respondents with elementary and ap-

Tab. 1: Mean value of EQ-5D score and mean value of EQ$5 \mathrm{D}$ VAS in dependence on age groups $(n=42, p<0,01)$.

\begin{tabular}{|l|c|c|c|c|}
\hline $\begin{array}{l}\text { Age range } \\
\text { (number of } \\
\text { respondents) }\end{array}$ & $\begin{array}{c}\text { Mean } \\
\text { EQ-5D } \\
\text { score } \\
\text { (in \%) }\end{array}$ & $\begin{array}{c}\text { Standard } \\
\text { deviation } \\
\text { of EQ-5D } \\
\text { score }\end{array}$ & $\begin{array}{c}\text { Mean } \\
\text { EQ-5D } \\
\text { VAS } \\
\text { (in \%) }\end{array}$ & $\begin{array}{c}\text { Standard } \\
\text { deviation } \\
\text { of EQ-5D } \\
\text { VAS }\end{array}$ \\
\hline $40-50(\mathrm{n}=2)$ & 69.5 & 13.8 & 60 & 14.2 \\
\hline $51-60(\mathrm{n}=10)$ & 71.8 & 15.2 & 73.3 & 15.8 \\
\hline $61-70(\mathrm{n}=17)$ & 66.4 & 12.6 & 61.6 & 11.8 \\
\hline $71-80(\mathrm{n}=13)$ & 57.9 & 9.3 & 53.8 & 9.1 \\
\hline
\end{tabular}

Tab. 2: Mean value of EQ-5D score and mean value of EQ$5 \mathrm{D}$ VAS in dependence on stage of PAOD in accordance with Fontaine classification $(\mathrm{n}=42, \mathrm{p}<0.01)$.

\begin{tabular}{|l|c|c|c|c|}
\hline $\begin{array}{l}\text { Stage of PAD } \\
\text { in accordance } \\
\text { with Fontaine } \\
\text { classification } \\
\text { (number of } \\
\text { respondents) }\end{array}$ & $\begin{array}{c}\text { Mean } \\
\text { EQ-5D } \\
\text { score }\end{array}$ & $\begin{array}{c}\text { Standard } \\
\text { deviation } \\
\text { of EQ-5D } \\
\text { score }\end{array}$ & $\begin{array}{c}\text { Mean } \\
\text { EQ-5D } \\
\text { VAS } \\
\text { (in \%) }\end{array}$ & $\begin{array}{c}\text { Standard } \\
\text { deviation } \\
\text { of EQ-5D } \\
\text { VAS }\end{array}$ \\
\hline IIa $(n=4)$ & 75.8 & 15.2 & 77.5 & 14.8 \\
\hline $\begin{array}{l}\text { IIb }(<200 \mathrm{~m}) \\
(\mathrm{n}=16)\end{array}$ & 69.9 & 14.1 & 67.8 & 13.9 \\
\hline $\begin{array}{l}\text { IIb }(<50 \mathrm{~m}) \\
(\mathrm{n}=9)\end{array}$ & 61 & 13.5 & 54.1 & 11.8 \\
\hline III $(\mathrm{n}=6)$ & 55.8 & 12.4 & 51.7 & 13.2 \\
\hline IV $(\mathrm{n}=7)$ & 61.1 & 13.6 & 58.3 & 12.6 \\
\hline
\end{tabular}

Tab. 3: Mean value of EQ-5D score and mean value of EQ5D VAS in all respondents with PAOD $(n=42)$.

\begin{tabular}{|c|c|c|}
\hline $\begin{array}{c}\text { Type of } \\
\text { QoL index }\end{array}$ & $\begin{array}{c}\text { Mean value } \\
\text { (in \%) }\end{array}$ & $\begin{array}{c}\text { Standard } \\
\text { deviation }\end{array}$ \\
\hline EQ-5D score & 65.3 & 13.1 \\
\hline EQ-5D VAS & 61.9 & 14.5 \\
\hline
\end{tabular}


prentice level education was 24 . The number of people of faith was 20 and non-believer was 24 . The number of respondents with coronary artery disease was 10 and the number of respondents with cerebrovascular manifestations of atherothrombosis was 6 . The coronary artery disease with simultaneous cerebrovascular manifestations of atherothrombosis had 4 respondents. None of the respondents ever had revascularization operation (surgical and endovascular intervention) on peripheral arterial circulation or sympatectomy and limb amputation.

The statistical evaluation present statistically significant dependence of QoL in respondents with PAD on age ( $p$ 0,01 ) (see Tab. 1) and stage of PAOD in accordance with Fontaine classification ( $p<0,01)$ (see Tab. 2). The effect of other health, demographic and psychosocial aspects was stastitically non-significant. The global QoL in respondents with PAOD is on low level (see Tab. 3).

\section{Discussion and Conclusion}

Our results have shown that with increasing age and with a serious stage of PAOD in accordance with Fontaine classification, the QoL declines. The global QoL in respondents with PAOD is low. We think that our results correspond to the fact that PAOD is a chronic disorder characterized by exertional limb pain, loss of limb, and a high mortality rate. Because of its chronic nature, it often has a negative impact on patients QoL.

The QoL means more dimensional evaluation of a number of aspects of life. Different aspects can be affected in a different way in a different phase of the disease and its treatment (5-7). That is why this information enriches our knowledge concerning patients' needs and it can significantly contribute to the medical treatment improvement. It can also help us to reveal the mechanisms which modify the origin and the course of disease $(6-8,10)$.
It is common in the clinical medical practice to evaluate a patient's health condition and the success of the treatment based only on one type of marker, the most often by means of somatic, laboratory or detecting markers. But the trend in modern clinical medicine is to evaluate a patient's health condition in a more complex way, using other aspects.

In conclusion, our study presents the effect of selected health, demographic and psychosocial aspects on QoL in respondents with PAOD. Our study is the first to probe into QoL of respondents with PAOD in our country.

\section{Acknowledgements}

The study was supported by Research Project of the Ministry of Defence of the Czech Republic No. 0FVZ0000503.

\section{References}

1. Chochola M, Linhart A. Epidemiology of peripheral arterial occlusive disease. Cas Lek Cesk. 2006;145:368-70.

2. Hirsch AT, M Reich L. Intermittent Claudication. Curr Treat Options Cardiovasc Med. 2001;3:167-80.

3. Puchmayer V, Roztočil K. Practical Angiology. Triton, Praha, 2000;60-3.

4. Shechter M, Auslander G, Weinmann EE, Bass A. Quality of life and social support following distal arterial bypass in elderly patients. Isr Med Assoc J. 2003;5: 322-5.

5. Slováček L, Slováčková B, Chovanec V. Peripheral arterial occlusive disease versus depression symptoms and quality of life. Cas Lek Cesk. 2006;145:788-91.

6. Slováček L, Slováčková B, Chovanec V et al. Quality of life of patients with peripheral arterial occlusive disease treated by means of endovascular intervention (percutaneous transluminal angioplasty. Interv Akut Kardiol. 2006;5:170-3.

7. Slováček L, Slováčková B, Chovanec V, Jebavý L. Perkutaneous transluminal angioplasty (PTA) and quality of life - the effect of PTA on quality of life of patients with peripheral arterial occlusive disease: partial results of prospective and longitudinal study. Zdravotnictví v České republice 2006;9:164-5.

8. Slováček L. Quality of life of patients with PAOD. Medical Tribune 2007, 3: A13.

9. The EuroQol Group. EuroQol - a new facility for the measurement of health-related quality of life. Health Policy 1990;37:671-7.

10. Treat-Jacobson D, Halverson SL, Ratchford A, Regensteiner JG, Lindquist R, Hirsch AT. A patient-derived perspective of health-related quality of life with peripheral arterial disease. J Nurs Scholarsh. 2002;34:55-60.

Submitted February 2007. Accepted April 2007.

\section{Corresponding author:}

Ladislav Slováček, M.D., Ph.D., major, University of Defence, Faculty of Military Health Science, Department of Field Internal Medicine, Trebešská 1575, 50001 Hradec Králové 1, Czech Republic, e-mail: ladislav.slovacek@seznam.cz 